This item was submitted to Loughborough's Research Repository by the author.

Items in Figshare are protected by copyright, with all rights reserved, unless otherwise indicated.

\title{
Investigation of the effect of metallic frames on $4 G$ eyewear antennas
}

PLEASE CITE THE PUBLISHED VERSION

http://dx.doi.org/10.1109/LAPC.2014.6996320

\section{PUBLISHER}

(c) IEEE

\section{VERSION}

AM (Accepted Manuscript)

\section{PUBLISHER STATEMENT}

This work is made available according to the conditions of the Creative Commons Attribution-NonCommercialNoDerivatives 4.0 International (CC BY-NC-ND 4.0) licence. Full details of this licence are available at: https://creativecommons.org/licenses/by-nc-nd/4.0/

\section{LICENCE}

CC BY-NC-ND 4.0

\section{REPOSITORY RECORD}

Cihangir, Aykut, Cyril Luxey, Gilles Jacquemod, Romain Pilard, Frederic Gianesello, W.G. Whittow, and C.J. Panagamuwa. 2019. "Investigation of the Effect of Metallic Frames on 4G Eyewear Antennas". figshare. https://hdl.handle.net/2134/26555. 


\title{
Investigation of the Effect of Metallic Frames on 4G Eyewear Antennas
}

\author{
Aykut Cihangir ${ }^{1}$, Cyril Luxey ${ }^{1}$, Gilles Jacquemod ${ }^{1}$, Romain Pilard ${ }^{2}$, Frédéric Gianesello ${ }^{2}$, Will G. Whittow ${ }^{3}$, Chinthana J. \\ Panagamuwa $^{3}$ \\ ${ }^{1}$ EpOC, University of Nice-Sophia Antipolis, Valbonne, FRANCE \\ ${ }^{2}$ STMicroelectronics, Crolles, FRANCE \\ ${ }^{3}$ Loughborough University, Loughborough, UK
}

\begin{abstract}
In this paper, we investigate the effect of metallic eyewear frames on the reflection coefficient, the radiation pattern and the specific absorption rate (SAR) of 4G antennas integrated in eyewear. The antennas used in the study are Coupling Element type, with appropriate matching networks to cover simultaneously the $700-960 \mathrm{MHz}$ and $1.7-2.7 \mathrm{GHz}$ frequency bands. Two different antenna locations are evaluated: behind the user's ear and at the opposite corner of the printed circuit board, close to the eye. For both antennas, the effect of metallic frames is investigated through numerous simulations. Compared to the case without metallic frame, the matching and radiation patterns are slightly affected. Although there is a redistribution of the SAR hotspots inside the head, the change in the $1 \mathrm{~g}$ and $10 \mathrm{~g}$ SAR values are marginal as a result of including the metallic frame.
\end{abstract}

Keywords-4G antenna, matching network, metallic frame, SAR, eyewear

\section{INTRODUCTION}

Smart eyewear devices are gaining popularity with several products already available from different companies. An example of such devices can be found in [1]. Currently, the wireless connectivity of these devices is limited to Wi-Fi and Bluetooth which means the eyewear might connect either to a hotspot or a peripheral smartphone if network access is needed. Concerning possible future advancements like integrating these devices directly to the cellular network, several antenna topologies were initially proposed by the authors in the feasibility study presented in [2]. These antennas were of Coupling Element (CE) type, directly printed on one side of the FR4 printed circuit board (PCB), having an appropriate matching network (MN) at the antenna feed to operate simultaneously in the $4 \mathrm{G}$ frequency bands: 700$960 \mathrm{MHz}$ and $1.7-2.7 \mathrm{GHz}$.

Previously, it was demonstrated in [3-6] that the nearby electromagnetic (EM) fields generated by a mobile phone antenna close to the user's head might be strongly modified when the user is wearing eyewear glasses with metallic frames or even jewelry or piercing. This is mainly due to the secondary currents which are induced on these metallic parts from the primary sources (antenna currents). It was also demonstrated that metallic frames have also a strong influence on the distribution of the EM fields in the head of the user. Moreover, new hotspots can be observed, for example in the eyes at certain frequencies. In this paper, the effect of using a metallic eyewear frame on the antenna parameters and SAR is investigated for a user wearing a smart eyewear device incorporating the $\mathrm{CE}$ type antennas as presented in [2]. The Specific Anthropomorphic Mannequin (SAM) head phantom is used in radiation pattern and S-parameter simulations, which is a standardized shape, widely used in SAR studies enabling compatibility with measurements as in [7].

\section{SimUlation MODELS}

The antennas and metallic frame models used in the simulations can be seen in Fig. 1, together with the homogeneous SAM head phantom. The frame is modeled as a curved block tracing the head model, above the FR4 PCB with a separation of $2 \mathrm{~mm}$. The ground plane is printed on the outer side of the substrate, with a length of $120 \mathrm{~mm}$. For Antenna-1, a $\mathrm{CE}$ is printed on the inner side of the $\mathrm{PCB}$, behind the user's ear. For the second model, the $\mathrm{CE}$ is placed on the other corner of the PCB, close to the user's eye. The MN at the feed of Antenna-1 consists of a series capacitor (1.6pF) and a shunt inductor $(14 \mathrm{nH})$, whereas the $\mathrm{MN}$ for Antenna-2 has two series inductors $(8 \mathrm{nH}$ and $12 \mathrm{nH})$ and a shunt capacitor $(0.2 \mathrm{pF})$. The simulations were performed using the commercial software EMPIRE XCcel [8].

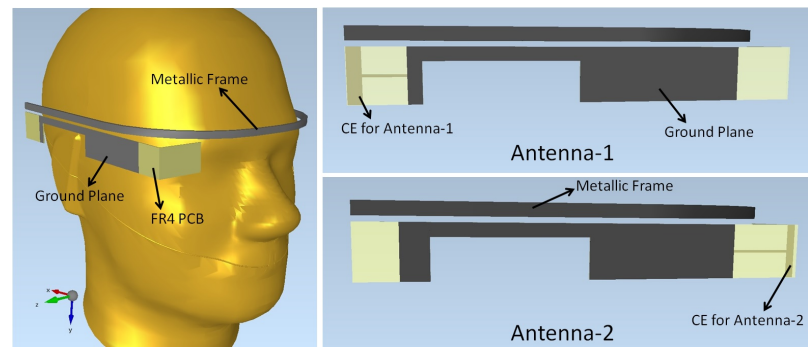

Fig. 1. Antenna Simulation Models

\section{EFFECT OF THE METALLIC FrAMES}

\section{A. Input Impedance of the Antennas}

Simulations were performed for both antenna-1 and antenna-2 with and without the metallic frame to see the effects on the input impedances of the antennas. The comparison of the reflection coefficients with and without the frame is presented in Fig. 2 for Antenna-1 and Fig. 3 for 
Antenna-2. For both, it is possible to claim little detuning in the reflection coefficient concerning the target band, due to the existence of the metallic frame. However, some overshoot around the edge of the higher band is observed, around 2.52.7GHz.

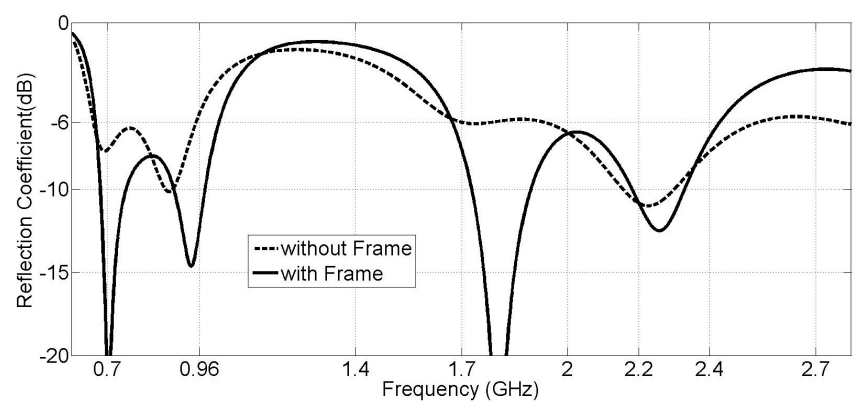

Fig. 2. Reflection Coefficient for Antenna-1

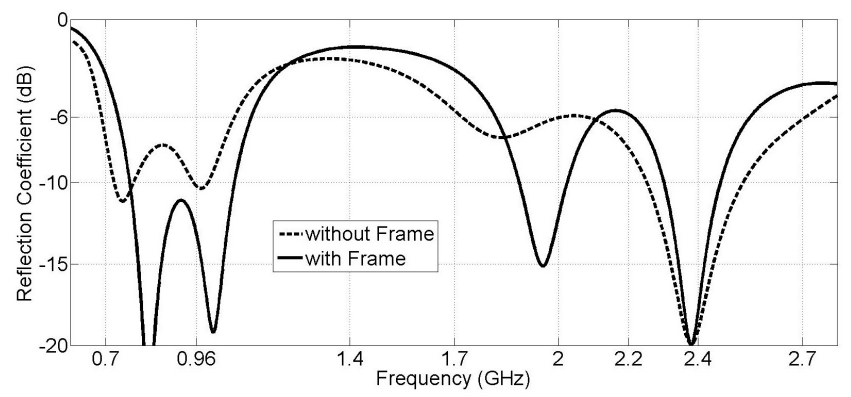

Fig. 3. Reflection Coefficient for Antenna-2

The radiation efficiencies of the antennas, with and without the frame are comparable. The simulated radiation efficiency for the first antenna without frame is between 7$10 \%$ in the LB $(700-960 \mathrm{MHz})$ and between $22-25 \%$ in the HB $(1.7-2.7 \mathrm{GHz})$. In the existence of the metallic frame, the LB radiation efficiency is between $5-7 \%$ and the $\mathrm{HB}$ efficiency is between $21-28 \%$. Likewise, the second antenna has radiation efficiencies between $14-16 \%$ in LB and between $33-41 \%$ in $\mathrm{HB}$, changing to $9-21 \%$ in $\mathrm{LB}$ and $30-44 \%$ in $\mathrm{HB}$ with metallic frame.

\section{B. Radiation Patterns}

The directivity patterns for Antenna-1 and Antenna-2 are given respectively in Fig. 4 and Fig. 5. As seen from all the patterns without the metallic frame at 800 and $2200 \mathrm{MHz}$, a null is observed in $-\mathrm{z}$ direction due to the absorption in the head. When the metallic frame is taken into account, at low frequencies, two additional lobes are observed towards - $\mathrm{x}$ and $-\mathrm{z}$ directions. To investigate the reason of the modified radiation patterns, the current distributions on the metallic frame are plotted in Fig. 6 (for antenna-1) and Fig. 7 (for antenna-2) respectively at $800 \mathrm{MHz}$ and $2200 \mathrm{MHz}$. As observed from these current distributions, there is a strong capacitive coupling from the near-field of the antenna and ground plane to the metallic frame especially in the lower frequency bands, where the $470 \mathrm{~mm}$ long frame corresponds to approximately 1.5 free space wavelengths (keeping in mind also the dielectric loading due to the lossy head). At $2200 \mathrm{MHz}$, the fields coupled from the antenna launches a travelling wave on the frame, whose strength reduces towards the other end of the frame. All in all, those induced currents on the metallic frame are causing it to radiate and the combination of the radiation from the $\mathrm{CE}$ (with the ground plane) and from the metallic frame currents result in the simulated radiation patterns shown in Fig. 4 and Fig. 5.

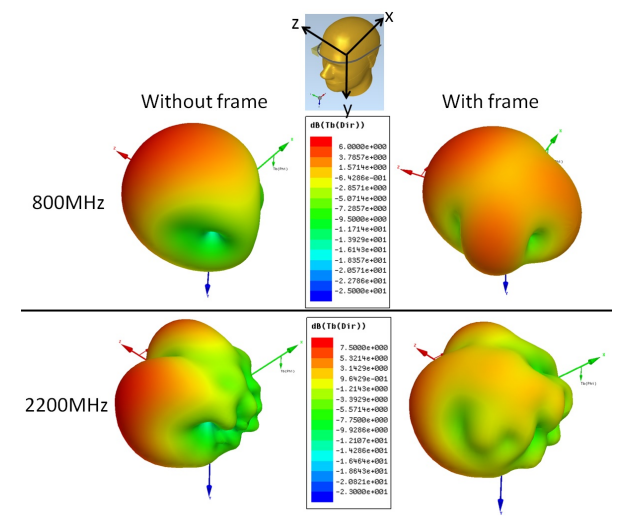

Fig. 4. Directivity Patterns for Antenna-1

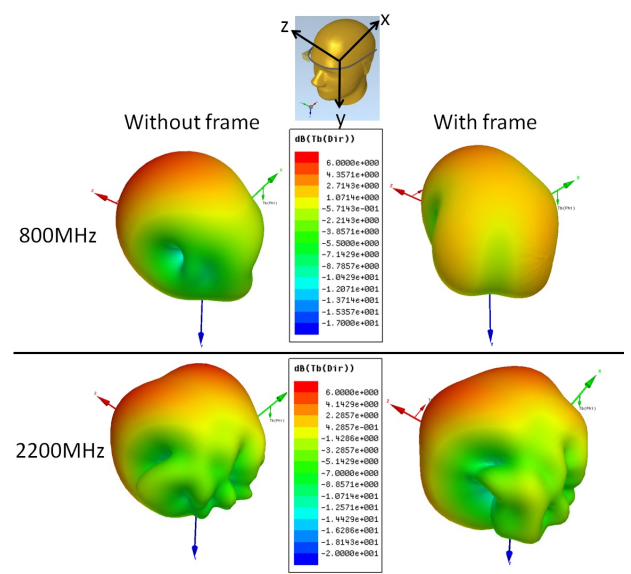

Fig. 5. Directivity Patterns for Antenna-2

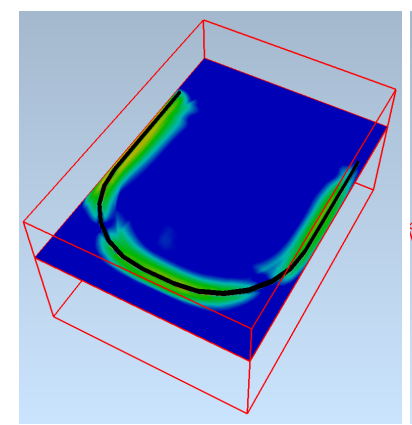

(a)

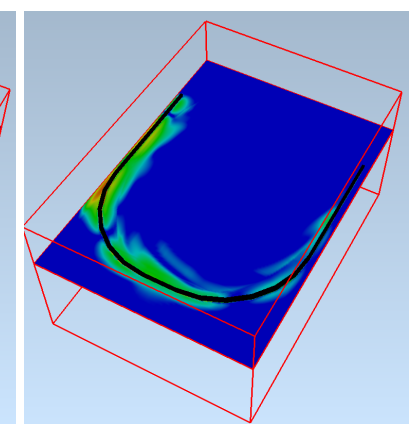

(b)

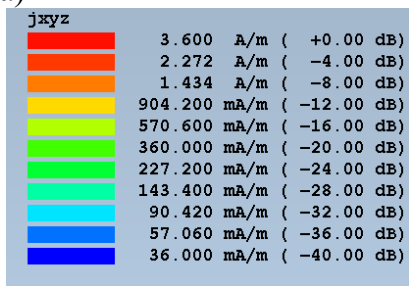

(c)
Fig. 6. Current distribution over the metallic frame for antenna-1, (a) $800 \mathrm{MHz}$, (b) $2200 \mathrm{MHz}$ and (c) the scale used for the two plots 


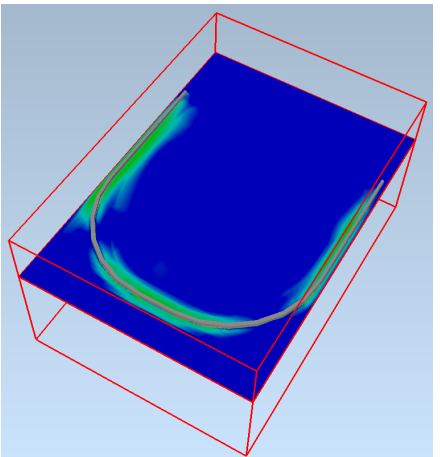

(a)

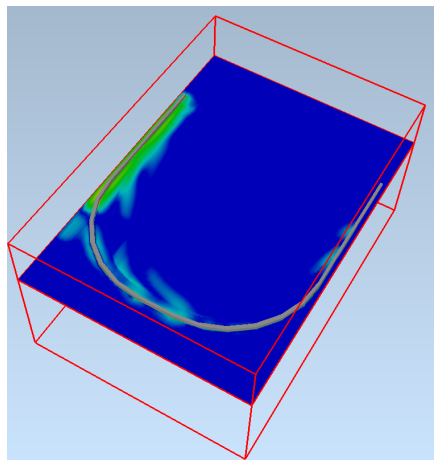

(b)
Fig. 7. Current distribution on the metallic frame for antenna-2, (a) $800 \mathrm{MHz}$, and (b) $2200 \mathrm{MHz}$

\section{Specific Absorption Rate (SAR)}

Specific Absorption Rate is the power absorbed per unit mass of tissue $(\mathrm{W} / \mathrm{kg})$ : it is the standard dosimetric parameter used worldwide. Europe defines a SAR limit of $2 \mathrm{~W} / \mathrm{kg}$ averaged over 10 grams of tissue for 6 minutes while the USA sets a slightly stricter limit of $1.6 \mathrm{~W} / \mathrm{kg}$ over 1 gram of tissue for 30 minutes.

To see the effect of the metallic frame on SAR, simulations were performed with a heterogeneous Visible Human head model, which is composed of different tissues, each of them modeled with their specific electrical properties. In this way, the SAR distribution in different parts of the head can be observed. It was shown in [2] that the simulated reflection coefficient using a heterogeneous $\mathrm{VH}$ model agrees fairly well with the simulations using homogeneous head phantom. Table I summarizes the simulated SAR values (for $1 \mathrm{~g}$ averaging and $10 \mathrm{~g}$ averaging) for the two antennas, with and without the metallic frame. All the SAR values are normalized to $0.25 \mathrm{~W}$ accepted power fed to the antenna by its port. The values that comply with the aforementioned SAR standards are shown in bold. The first thing to notice from the table is that the SAR values averaged over 1 gram of tissue is almost always higher than the $1.6 \mathrm{~W} / \mathrm{kg}$ limit. The opposite is true for $10 \mathrm{~g}$ averaged SAR, since almost all the values are below or close to $2 \mathrm{~W} / \mathrm{kg}$ limit. The effect of the metal frame seems minimal on the SAR, not causing significant changes in most of the frequencies. Generally, the SAR with the frame is slightly lower than the "without frame" case.

Fig. 8 presents the 1g SAR distribution for antenna-1 in the head at $835 \mathrm{MHz}$, with and without the metallic frame (together with the SAR scale normalized for $0.25 \mathrm{~W}$ power). The animation cut is in the zx plane passing through the centre of the eyewear and the eyes, as shown in (Fig. 8c). For the "without frame" condition (Fig. 8a), as expected, the maximum $1 \mathrm{~g} \mathrm{SAR}$ is seen on the side of the head closest to the antenna. When the metallic frame exists (Fig. 8b), there is an obvious redistribution of the energy to the rest of the head, increasing the $1 \mathrm{~g}$ SAR on the other side of the head, which is a result from the currents induced on the frame. Another important observation is the creation of secondary hot-spots (regions having higher SAR than their surroundings, which did not appear without frame) around the front of the eyes, which in turn considerably increases the $1 \mathrm{~g}$ SAR values. For example, the 1g SAR in the left eye is subject to an increase of approximately 250 times with the introduction of the metallic frames, although the maximum SAR is not observed here. Concerning this issue, it can be claimed that the existence of the metallic frame redistributes the $1 \mathrm{~g} \mathrm{SAR}$ in the head, by slightly decreasing the maximum $1 \mathrm{~g}$ SAR seen on the side of the head close to the antenna. However, the SAR increases significantly on the other side of the head, as well as in specific regions like the eyes.

TABLE I

SAR VALUES IN VISIBLE HUMAN PHANTOM (W/KG) NORMALIZED TO $0.25 \mathrm{~W}$ ACCEPTED POWER

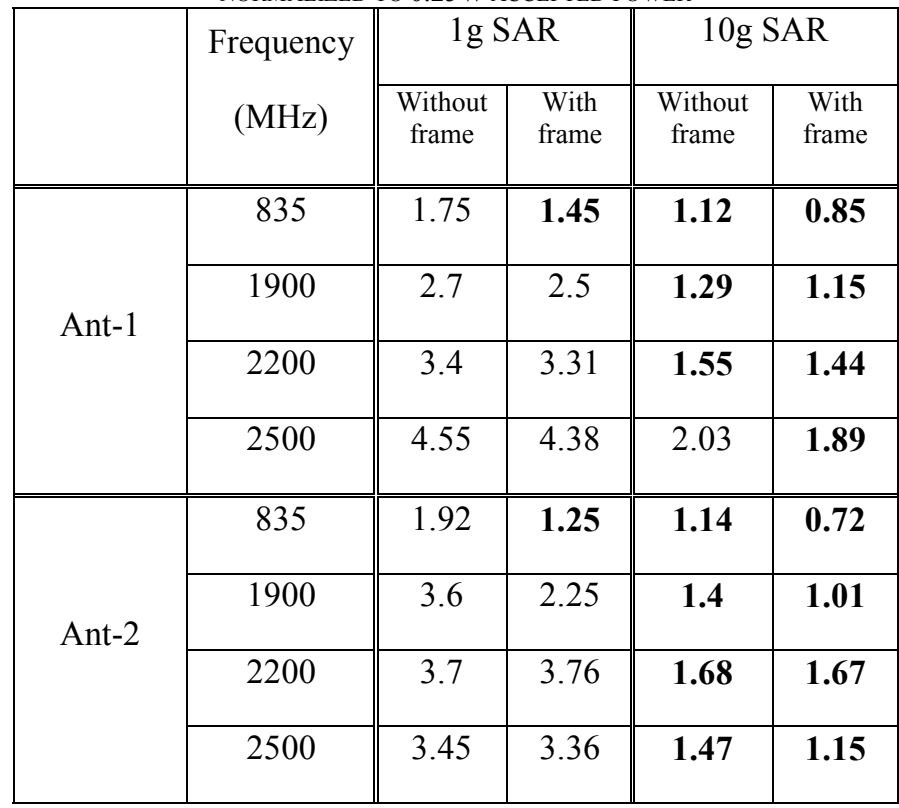

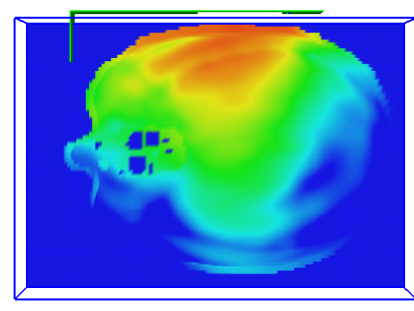

(a)

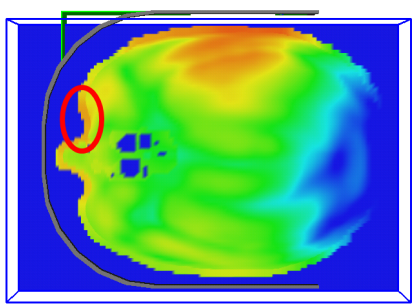

(b)

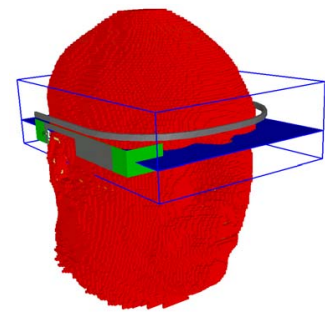

(c)

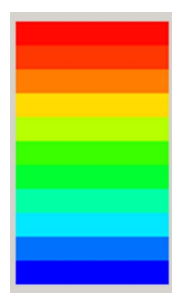

(d)

d)

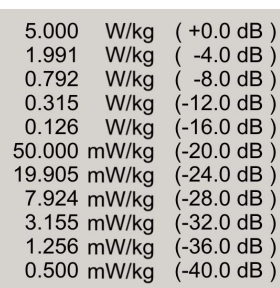

Fig. 8. 1g SAR distribution in the head for antenna-1 at $835 \mathrm{MHz}$, without the frame (a), with the metallic frame (b), location of the animation plane (c) and the scale used for $1 \mathrm{~g}$ SAR plots $(\mathrm{c})$ 
The SAR distribution for antenna-1 at higher frequencies is presented in Fig. 9, plotted using the same scale. For both $1900 \mathrm{MHz}$ and $2500 \mathrm{MHz}$, the energy penetration into the head is decreased when compared to $835 \mathrm{MHz}$. With the introduction of the metallic frame (plots on the right), the $1 \mathrm{~g}$ SAR on the far side of the head is again increased, also increasing the $1 \mathrm{~g}$ SAR around the eyes.

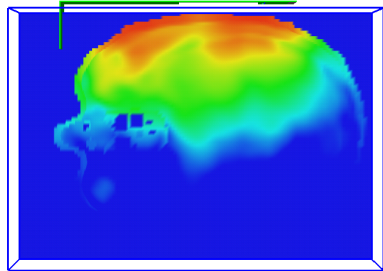

(a)

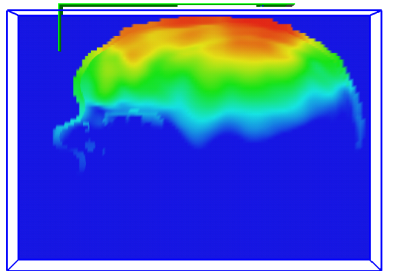

(c)

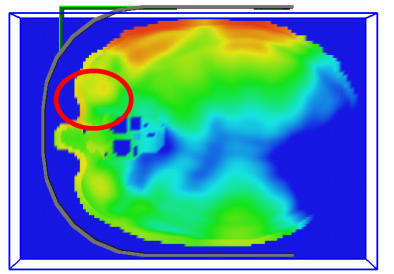

(b)

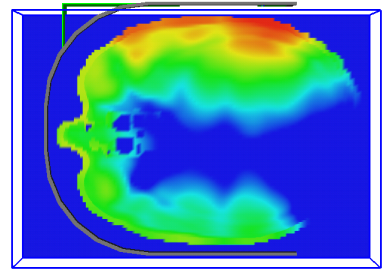

(d)
Fig. 9. 1g SAR distribution on the head for antenna-1, (a) without the frame at $1900 \mathrm{MHz}$, (b) with the frame at $1900 \mathrm{MHz}$, (c) without the frame at $2500 \mathrm{MHz}$, (d) with the frame at $2500 \mathrm{MHz}$

The same comments can be made for the $1 \mathrm{~g}$ SAR distribution of antenna-2, shown in Fig. 10. The maximum $1 \mathrm{~g}$ SAR on the side of the head is slightly reduced with the introduction of the frame. However, owing to the currents induced on the frame, the SAR on the other side of the head increases significantly. Secondary hot-spots can again be observed in specific regions like the eyes.

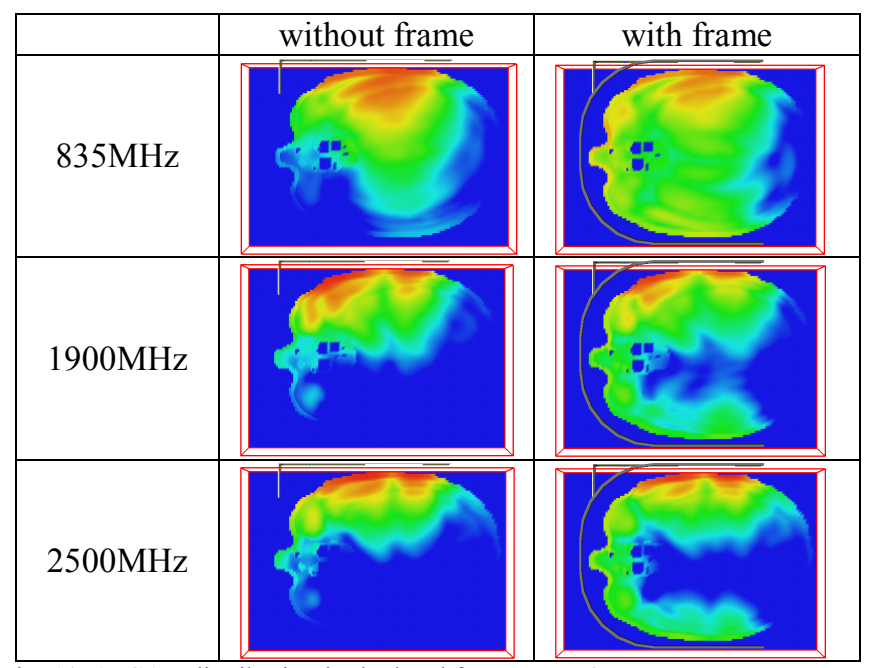

Fig. 10. 1g SAR distribution in the head for antenna-2

\section{CONCLUSION}

The effect of metallic frames on the reflection coefficient, radiation patterns and SAR for $4 \mathrm{G}$ antennas for eyewear devices was investigated in this paper. Coupling element type non-resonant antennas were used, which are tuned to operate in $700-960 \mathrm{MHz}$ and $1.7-2.7 \mathrm{GHz}$ frequency bands using matching networks at the antenna feed. It was demonstrated through simulations that metallic frames can affect the antenna behavior by the currents induced on them. The radiation patterns can be significantly modified especially in the lower frequencies because of the radiation of the excited currents on the frame. The maximum $1 \mathrm{~g}$ SAR levels, simulated with a heterogeneous head model showed minimum deviation when compared to "without frame" case, however the SAR distribution on the whole head was changed considerably. Especially, the $1 \mathrm{~g}$ SAR on the other side of the head was significantly increased, creating secondary hot-spots in specific tissues of the head. By their very nature, smart eyewear devices need to be placed parallel to the eyes, in order to allow the user to view the screen. Therefore, antenna designers for these types of devices are likely to see the SAR in the eye increase and so will need to pay particular attention to this area.

\section{REFERENCES}

[1] http://www.google.com/glass/start/

[2] A. Cihangir, W.G. Whittow, C.J. Panagamuwa, F. Ferrero, G. Jacquemod, F. Gianesello, C. Luxey, "Feasibility Study of 4G Cellular Antennas for Eyewear Communicating Devices," IEEE Antennas and Wireless Propagation Letters, vol. 12, pp. 1704-1707, 2013.

[3] G. Bellanca, G. Caniato, A. Giovannelli, P. Olivo, S. Trillo, "Effect of field enhancement due to the coupling between a cellular phone and metallic eyeglasses," Microwave and Optical Technology Letters, vol. 48, no. 1, pp. 63- 65, January 2006.

[4] W. G. Whittow and R. M. Edwards, "A study of changes to specific absorption rates in the human eye close to perfectly conducting spectacles within the radio frequency range 1.5 to $3.0 \mathrm{GHz}$," IEEE Trans. on Antennas and Propag., vol. 52, no. 12, pp. 3207-3212, Dec. 2004.

[5] W.G. Whittow, C.J. Panagamuwa, R. Edwards, J.C. Vardaxoglou, "On the effects of straight metallic jewellery on the specific absorption rates resulting from face-illuminating radio communication devices at popular cellular frequencies," Phys. Med. Biol., vol. 53, pp. 1167-1182, 2008.

[6] C. J. Panagamuwa, W. G. Whittow, R. M. Edwards, J. C. Vardaxoglou, "A Study of the Effects of Metallic Pins on SAR using a Specific Anthropomorphic Mannequin (SAM) Head Phantom," The Second European Conference on Antennas and Propagation, EuCAP 2007, pp. 1,6 .

[7] C. J. Panagamuwa, W. G. Whittow, R. M. Edwards, J. C. Vardaxoglou, "Experimental Verification of a Modified Specific Anthropomorphic Mannequin (SAM) Head used for SAR Measurements, "Loughborough Antennas and Propagation Conference, LAPC 2007, pp.261,264, 2007.

[8] EMPIRE XCcel, Information available at: http://www.empire.de/ 